Research article

\title{
Antenatal screening and its possible meaning from unborn baby's perspective Sahin Aksoy*
}

\author{
Address: Harran University, Faculty of Medicine, Department of Medical Ethics and History of Medicine, 63200 Sanliurfa, TURKEY \\ E-mail: Sahin Aksoy* - saksoy@ harran.edu.tr \\ *Corresponding author
}

$\begin{array}{ll}\text { Published: } 22 \text { May 200I } & \text { Received: } 31 \text { March 200I } \\ & \text { Accepted: 22 May 200 I }\end{array}$

BMC Medical Ethics 2001, 2:3

This article is available from: http://www.biomedcentral.com/1472-6939/2/3

(c) 200 I Aksoy, licensee BioMed Central Ltd.

\begin{abstract}
In recent decades antenatal screening has become one of the most routine procedure of pregnancy-follow up and the subject of hot debate in bioethics circles. In this paper the rationale behind doing antenatal screening and the actual and potential problems that it may cause will be discussed. The paper will examine the issue from the point of wiew of parents, health care professionals and, most importantly, the child-to-be. It will show how unthoughtfully antenatal screening is performed and how pregnancy is treated almost as a disease just since the emergence of antenatal screening. Genetic screening and ethical problems caused by the procedure will also be addressed and I will suggest that screening is more to do with the interests of others rather than those of the child-to be.
\end{abstract}

\section{Introduction}

Antenatal testing (ANT) is widely used in modern obstetrics and gynaecology. I shall discuss the procedures involved in ANT from different perspectives, beginning with definitions of 'antenatal screening' and 'antenatal diagnosis', the main objectives and indications for their use. Secondly, I will discuss the risks and complications of ANT, the concerns, doubts and moral controversies it raises. Thirdly, since counselling is an integral part of ANT, I shall try to determine what the ideal of counselling before and after ANT is meant to be. Finally, with particular reference to some relevant concepts like 'responsibility', 'suffering' and 'interest', I attempt to describe the whole issue more comprehensively.

Recent studies have indicated that the major paediatric health problems are handicaps due to genetic disorder or congenital malformation. When it was noticed that more than a quarter of all deaths in the first year of life were due to fetal abnormalities [1], scientists were alarmed and parents sought a 'remedy' for the 'problem'. Although antenatal diagnostic techniques were initially described in the nineteenth century, it was not until the middle of 2oth century that the techniques were applied to AND and management of various genetic disorders and congenital malformations. And, at the present time, antenatal screening and diagnostic techniques are almost the norm. It has been said that, probably around $90 \%$ of women in the UK have undergone one of these at some time during pregnancy [2]. Although there is only a slight difference between the two procedures, the authorities do distinguish between antenatal screening (ANS) and antenatal diagnosis (AND).

\section{Aims of antenatal testing}

ANS services are based on population screening to identify people with a genetic risk, or a risk of having a child with a congenital or genetic disorder [3]. In the Dutch Health Council report on genetic screening, the major aim is defined as: "To enable people to decide upon a 
course of action that is acceptable for them" [3]. ANS includes:

1. Screening for sporadic conditions affecting the fetus (infections, chromosomal disorders, malformations, maternal diabetes);

2. Family history for genetic risks;

3. Population screening for carriers of common recessively inherited diseases.

Different health authorities in different countries have pointed out various aspects of ANS. While the Danish Health Council considers screening as a communitybased form of help based on the obligation to help the weak, the Nuffield Council on Bioethics (in Britain) points out that, although the primary aim seems to be to improve the health of persons suffering from genetic disorders, the benefits should include enabling individuals to take account of the information for their own lives, and empowering them as prospective parents to make informed choices about having children [3].

Although the screening test is not usually in itself diagnostic, it detects a subgroup of those tested who are at higher risk of having the disease or disorder than the original population screened, in many cases it is possible to make diagnoses with considerable accuracy.

Three different types of ANS methods are widely used;

1. Biochemical Screening In this technique, a single specimen of blood taken from a pregnant women at about 16-18 weeks of pregnancy, can be used to screen for Down's Syndrome and open neural-tube defects. This can detect about 60\% of pregnancies with Down's Syndrome, about $90 \%$ of pregnancies with open spina bifida, and virtually all cases of anencephaly [4]. Biochemical screening tests are used to identify those women who are at high enough risk to justify the hazards and costs of the diagnostic procedures.

2. Genetic Screening The sensitivity and the specificity of genetic screening is fairly high. The test is carried out either by amniosentesis or by Chorionic Villus Sampling (CVS) at 14-16 weeks and 8-9 weeks respectively. Using standard cytogenetic techniques it is possible to culture amniotic fluid cells from as little as $10 \mathrm{ml}$. of amniotic fluid at 12 weeks, although successful culture before this time is currently less reliable. In CVS chorionic tissue obtained via endoscopic biopsy is used to make the types of fetal diagnoses by culture of amniotic fluid cells The objectives of genetic screening developed by the Royal College of Physicians (London) are:
- to allow the widest possible range of informed choice to women and couples at risk of having children with an abnormality.

- to allow couples to embark on having a family knowing that they may avoid the birth of seriously affected children through selective abortion.

- to ensure optimal treatment of affected infants through early diagnosis [4].

3. Ultrasound Screening The objectives of ultrasound screening are defined as:

-to reduce the prenatal mortality and morbidity; and

-to allow the identification of a group of babies for whom treatment in utero may be appropriate by defining structural abnormalities.

\section{Antenatal Diagnosis}

AND has four main purposes;

1) to inform and prepare parents for the birth of an affected infant;

2) to allow in utero treatment, or delivery at a specialist centre for immediate postnatal treatment;

3) to allow termination of an affected fetus;

4) to provide information so that parents may choose between 1,2 and 3 .

Evidently, the goal of AND is to help couples make an informed choice, one which they feel is best for themselves and their families. AND tests can be divided into those involving measurements of chemicals in maternal blood, imaging the fetus, and invasive tests to remove tissue of fetal origin. The tests in the last group may be carried out before 14 weeks' gestational age but after implantation, beyond 14 weeks' gestational age, or in the pre-implantation period. The tests, which are carried out in the preimplantation period are embryo biopsy and polar body analysis. The tests in the second group are fetal blood sampling, fetal tissue biopsy, amniocentesis, and transabdominal chorion biopsy. The tests in the first group, that are the most widely used at present, are early amniocentesis, transabdominal chorion villus biopsy or sampling (CVS) and transcervical CVS. Table 1 [5] indicated some of these antenatal tests with their time of application, and detectable conditions. 
Table I: Antenatal Tests

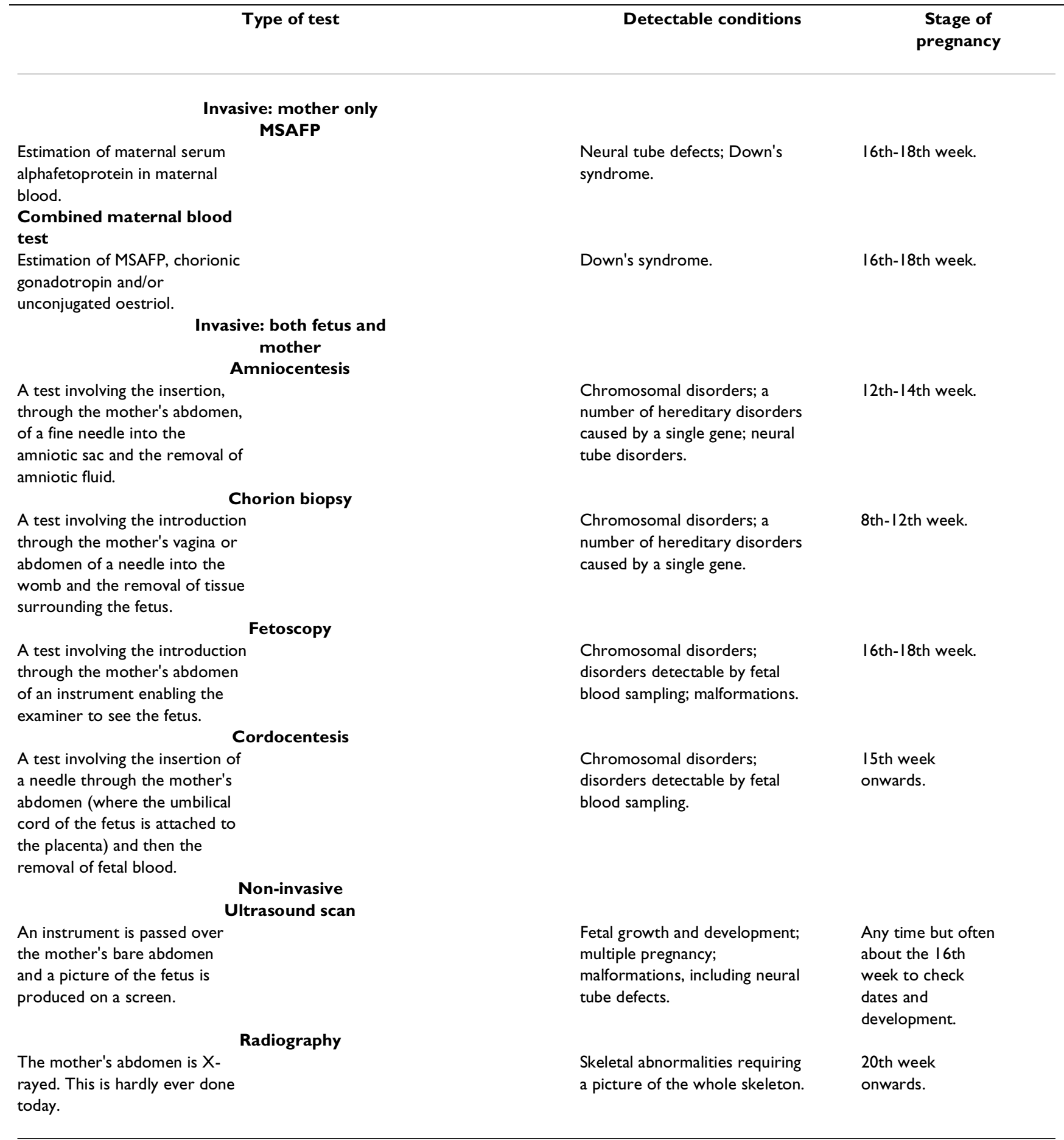

\section{Preimplantation Diagnosis (PID)}

Among other ANTs PID has a special feature. It aims to avoid the possibility of an affected pregnancy completely. It is based on the simple strategy of sampling genetic material from eggs or embryos within the first week of their development following fertilisation. The genetic material is used to detect whether a particular genetic defect is present and whether the embryo will be affected 
by it. This procedure theoretically enables the selection of only healthy embryos for implantation, or the genetic modification of embryos with disabilities or genetic defect prior to implantation. Beside other advantages PID is more abstract and less invasive than other AND technologies. PID is done at an earlier time than AND-up to five days as against ten-sixteen weeks. This may lessen feelings of emotional attachment in that PID can prevent termination of a pregnancy diagnosed as affected at later stages of gestation. It is argued that the earlier the diagnosis of genetic conditions, the easier the moral choices for many women or couples. For those who hold that the early fetus (i.e. 'pre-sentient' or not yet a 'person') is morally different from the older fetus, early identification of fetal genetic conditions will diminish the moral confusion of abortion [6]. R. G. Edwards, the pioneer of in vitro embryology, observed that: "Identifying embryos with genetic abnormalities would offer an alternative to amniocentesis during the second trimester of pregnancy, and the 'abortion in vitro', of a defective preimplantation embryo would be infinitely preferable to abortion in vivo at twenty weeks of pregnancy or thereabouts as the result of amniocentesis are obtained" [7].

Although it seems emotionally (perhaps also ethically) less problematic, there are still objections to the manipulation of human preimplantation embryos [8]. The objections are generally based on the view that there is, in principle, no difference between an eight-cell embryo, and a fetus or a child. In this view, they are all human individuals and, since informed consent is not possible, they should not be interfered with. On this basis, terminating an affected pregnancy halfway through the pregnancy is no more or less acceptable than discarding affected preimplantation embryos. The opposing view draws a sharp distinction between these stages of a human being's development and consequently argues that the ethical constraints are different at each stage. In this case, manipulation of early embryos to remove cells for genetic analysis is acceptable and some would argue that discarding affected embryos is preferable to doing so at later stages. Another concern about PID is that, after prenatal diagnosis, there is at least a theoretical possibility that a couple will decide to carry a genetically abnormal fetus to full-term. In the context of preimplantation diagnosis and IVF, the decision-making process is eliminated; the genetically abnormal embryo will not be implanted [9].

\section{Benefits of antenatal testing}

There can be a little doubt, on the face of it, that the techniques just described were devised to help people, and aim to enable parents to plan their future family knowledgeably. However, many authorities from various fields have expressed some serious concerns about them. It is important to define the 'real' aims of these techniques, and see how they work in practice. It is thought that these techniques may not necessarily have been developed with the interests of women primarily in mind, nor are necessarily applied to further women's interests [10]. A governmental document from DHSS (in United Kingdom) may help us to clarify our thinking about the 'real' aim of these technologies. It reads: "...because caring for the handicapped can impose great burdens on our society the prevention of handicaps...in addition to its other benefits may save money. The costs of providing amniocentesis for all expectant mothers over the age of 40 years, and maternal serum AFP screening for all pregnant women, would be more than offset by the economic benefits in terms of savings of expenditure on children and adults with Down's Syndrome and spina bifida" [11].

Rational as this sounds, this kind of rational-economic thinking may degrade society's willingness to accept and care for abnormal children, while at the same time enlarging the category of unacceptable abnormality and narrowing the range of acceptable normality. If Down's syndrome and spina bifida are 'too' expensive today, what will become 'too' expensive if the economic climate becomes gloomy [12]?

Whether and how far it is right to accommodate costbenefit analysis in the medical field has always been problematical. As has the question of whether economical considerations should affect clinical decisions [13]. Some reports have compared, for populations with varying incidence of neural tube defects, the benefits of a antenatal screening programme (in terms of number of births with neural tube defects prevented) against the physical costs (in terms of the number of normal fetuses harmed by amniocentesis) the cost-benefit ratio becomes progressively less favourable as the population incidence of neural tube defects decreases. This, together with the fact that around 85 per cent of babies with neural tube defects are either still-born or die within the first year of life, means that, in regions with a low incidence of neural tube defects, it is possible that more unaffected pregnancies may be harmed than handicapped children avoided [14]. Another recent report has also indicated the 'possible cost' of antenatal diagnosis. With its annual report, the Danish Council of Ethics has published a debate outline on ethical issues in fetal diagnostics. It consists of a report on the past, present and future of fetal diagnostics, commissioned from a Danish science writer, and a discussion of the Council's deliberations on the issue. The report reads "Just under 120,00o fetuses examined. Over 2,200 sick or deviant fetuses identified and aborted. Loss of some 1,100 presumably healthy fetuses as a side-effect of the examination used" [15]. The council sums up that "it is essential to stress that, irrespective 
of the stance taken on fetal diagnostics, it will be problematic for either one or the other party involved in fetal diagnostics". Table 2 [5] outlines the costs and benefits of AND typically noted by medical practitioners involved in AND. The table makes it clear that medical practitioners usually focus on the pregnant woman rather than on the fetus when they assess the advantages and disadvantages of antenatal diagnosis.

As the table shows, it is possible to argue that AND tests can benefit everyone but the prenate. However, there is no denying that AND can be a vital aid in monitoring pregnancies for therapeutic reasons with a view to safe deliveries, and most AND is performed in order to prevent the birth (or conception) of disabled children. This motivation is clearly expressed in the report of the Royal College of Physicians: "Unless prenatal diagnosis is to be devoid of practical application when it reveals a major defect in the fetus, a responsible doctor must discuss with the parents the option of terminating that pregnan- cy and must in some circumstances provide information that may deter them from further reproduction" [16]. The termination of pregnancy and its acceptability is taken elsewhere [17], but it is worth mentioning here that it is highly questionable to claim termination of pregnancy as in the 'child's best interest'.

It has been argued that the availability of antenatal screening and diagnostic testing has changed the experience of pregnancy. Before the development of antenatal testing for fetal abnormality, the fetus was assumed to be healthy, unless there was evidence to the contrary. The presence of antenatal testing and monitoring shifts the balance towards having to prove the health or normality of a fetus [18]. Pregnancy has come under medical control to such a degree that it is almost treated as a disease, and pregnant women have accepted their role as patients in need of medical help. Both the medical profession and pregnant women now regard antenatal diagnosis as a necessary part of prenatal care.

Table 2: Costs and benefits of antenatal diagnosis typically noted by the medical profession

\begin{tabular}{|c|c|}
\hline Costs & Benefits \\
\hline & For hospital and health authorities \\
\hline I) Costs in connection with diagnosis, & $\begin{array}{l}\text { I) Scarce resources allocated to children with good prognosis (rather than to severely handi- } \\
\text { capped children). }\end{array}$ \\
\hline 2) Costs involved in performing termination. & \\
\hline 3) Costs in connection with counseling services. & \\
\hline & For pregnant women and fathers-to-be \\
\hline & Availability of prenatal diagnosis \\
\hline & I) Increase in the number of healthy children born to parents at risk who, had prenatal diagnosis \\
\hline & not been available, would have avoided becoming pregnant. \\
\hline & Diagnostic procedures \\
\hline I) Risk of fetal loss or injury, & \\
\hline 2) Maternal hazards, & \\
\hline 3) Maternal anxiety. & \\
\hline & $\begin{array}{c}\text { Result: } \\
\text { true negative }\end{array}$ \\
\hline & 2) Reassurance, \\
\hline & $\begin{array}{l}\text { 3) An increase in the number of healthy children born to parents at risk who, had the test result } \\
\text { not been negative, would have terminated pregnancy on grounds of risk. } \\
\text { false negative }\end{array}$ \\
\hline 4) False reassurance. & false positive \\
\hline 5) Abortion of healthy fetus, & \\
\hline 6) Grief and adverse psychological consequences & \\
\hline of termination of non-affected pregnancy. & \\
\hline & true positive \\
\hline & -followed by abortion- \\
\hline 7) Grief and adverse psychological consequences & 4) Averted parental distress and burden of care for disabled child, \\
\hline & 5) Additional non-disabled children. \\
\hline & -not followed by abortion- \\
\hline & 6) Time to prepare for the birth of the disabled child. \\
\hline
\end{tabular}


Barbara Rothman, in her book The Tentative Pregnan$c y$, maintains that it is the medical profession that has created a need for antenatal diagnosis for 'reassurance' by creating what she calls 'genetic anxiety', thereby capitalising on women's normal fear of having a 'defective', socially unacceptable, child, just as deodorant and mouthwash companies first had to create anxiety about socially unacceptable body odour before they could market their product [19]. However, if there really is a normal fear of having a 'defective', socially unacceptable child, then it is the duty of health care professionals to find a solution. Rothman's critique may well be a response to a certain paternalism in the attitudes of the medical vis-à-vis ANT. As in many other medical interventions, informed consent and intelligent counselling are of prime importance in ANT procedure.

\section{Effect of counselling}

Counselling before and after ANT is crucial [20]. It is suggested that, in an ideal counselling, the parents should be told that there is no 'right' decision to be made, and it should be made clear that whatever their decision is, it will be supported. They must also be clear about whether it is a screening test or a diagnostic test, and how accurate it is in their particular situation. They need to be aware of the risks involved to the pregnancy and the possible consequences of dealing with the information the test provides [21]. Normally, medical professionals should not offer antenatal diagnosis, because it is known that it is very difficult for a woman to decline AND when offered [22]. Instead, they should discuss the feasibility, accuracy and clear-cut details of any such tests, including the dangers of it.

Three pieces of information which women tend to cite as reasons for changing their minds about tests are;

- the level of risk they have for the condition in question;

- the miscarriage risk of the test being considered;

- the method of termination which would be offered if they chose to terminate the pregnancy following an abnormal result from the test in question [21].

To provide this kind of ideal counselling, firstly there must be enough well-trained health care professionals. The units that provide these services must also provide suitable training opportunities and satisfy the expectations of users of ANT services.

Chadwick suggests that 'genetic counselling' includes the following kinds of activity: a) advising adults, pre-conception, of the probability of their conceiving a child with a genetic disorder;

b) advising adults, post-conception, and as a result of some method of fetal screening, as to whether or not the fetus is suffering from a genetic disorder;

c) alerting them to the options open to them [23].

Clearly, it is important to leave the final decision to the parents. Doctors are supposed to not impose their own moral attitudes upon their patients. If they find themselves disagreeing with the moral stance of their patients over these issues they should explain their situation and advise the patients to consult a clinical geneticist [24].

However, it seems it does not work like this in practice. Because, making rules does not mean everything. The most important and difficult thing is applying them. And this depends on the development of public awareness and education [25]. It is argued that the conflict of interests between providers and users of antenatal screening services is clearly reflected in the counselling process. At all stages of screening, counselling is systematically biased towards encouraging women to take up the tests and have an abortion if an abnormality is detected, rather than providing women with the information and support they require to make an informed choice and to avoid unnecessary distress [10]. The Medical Research Council (MRC) stated in its report that: "Of the 112 women (including high risk women) interviewed after they had had an amniocentesis, 28 (24 per cent) were unaware that amniocentesis carried a risk of miscarriage, and 96 (86 per cent) were unaware of any other possible hazards. Of the 16 women aware of the possible risks to the newborn infant, 12 had obtained this information from sources other than the medical staff who had counselled them about amniocentesis" [14]. There is literature available which is compatible with the MRC's report. For example: "Women undergoing routine antenatal screening are generally under-informed about the tests they are being offered and may subsequently undergo. For example, 39 per cent of women who had recently undergone maternal serum alphaprotein (MS-AFP) screening for open neural tube defects were unaware that they had even had the test" [26].

Self-evidently, this is not an ideal situation for any health care service. Apart from the failure to provide enough information, the bias toward termination of pregnancy in the event of abnormality detection is another controversy in AND procedure. It is generally conceded by the medical profession that the primary aim of antenatal diagnosis is the detection, and subsequent abortion, of abnormal fetuses. Because of the procedural risks to the 
fetus and the lack of effective methods of fetal therapy for most malformations, antenatal diagnosis is a rational activity only if abortion is seen as an acceptable alternative [27]. However, this kind of approach to prenatal diagnosis may be considered not only unfair, but also rather unethical, by some people.

In order to describe the feelings of parents who are pushed to have a termination, one needs to have experienced it. But it is not too hard to comprehend the difficulty for parents who decide not to terminate a pregnancy with a diagnosed fetal abnormality-they must face, as well as the distress of coping with a handicapped child, the mental and emotional struggle of defending their decision before health professionals [28]. In an ideal ANT procedure, health care professionals are expected to strengthen their role as providers of support to the families for whom they care. They should provide moral support and practical help both to those who terminate fetuses at risk of malformation or disease and to those who choose not to do so. Furthermore, ANT providers in this field are expected to prevent any possibility that financial considerations might affect clinical behaviour. Angus Clarke, a clinical geneticist, makes a distinction between giving advice-a prescriptive activity, often subtly authoritarian when applied to the field of personal reproductive decisions-and the informing, supportive, and 'enabling' process of counselling [29]. And he adds: "We do not tell people what to do but support them in reaching decisions, with the consequences of which they then have to live for the rest of their lives. We may have to inform clients about the disadvantages of their preferred course of action so that they can examine all options (such as a permanently handicapped child, or permanent remorse at a termination), but, when the decision is genuinely their own, the parents are much more likely to be able to live with it" [29].

Another counselling issue related to ANT is that of directiveness. It has been argued that pre-test counselling should be non-directive since it is counsellee and not the counsellor whose entire future life may be affected by decisions made at the sessions. However, those present at the Third European Meeting on Psycho-social Aspects of Genetics (1992) voted by a narrow majority that non-directive genetic counselling was not achievable in practice. This is partly due to the fact that counsellors come to sessions with their own views about what they think they would do in the situation or what they think a responsible person should do. These views may be held consciously or unconsciously but they will influence the counsellors' choice of words in describing conditions, tests and probabilities, their facial expression, body language, and the order in which things are explained and the amount of time spent on different topics. For this reason non-directive counselling is thought to be an unattainable ideal. It is not because of a personal failure on the part of the genetic counsellor but as a direct result of the structure of the encounter between counsellor and client [30]. Clarke argues that the counsellor's conscious or even unconscious motives are irrelevant; the offer and acceptance of genetic counselling has already set up a likely chain of events in everyone's mind [30].

From all these discussions it becomes apparent that nondirective counselling is a myth. Today, counselling is directive, and its direction is towards having ANT and going to termination if something is wrong with the 'baby in the womb'. Let us now discuss (in terms of its benefits to different parties) the consequences of ANT.

\section{Consequences of antenatal testing}

The primary purpose of AND is to relieve parents of anxiety over inheriting a genetic disease, or giving birth to a child with congenital abnormalities (e.g. for older women), and this is the major outcome. AND is defined as intended to inform parents of the birth of an affected infant, to allow in utero treatment, or delivery at a special centre for immediate postnatal treatment, or to allow termination of an affected fetus; in practice the last of these three has become the most used course of action. Many writers have criticised this attitude as wrong. Among the argument put forward is that wide acceptance of selective abortion diminishes the importance of and the motivation for, research on cures for genetic disorders, whether in utero or after birth to be taken up.

There is a little doubt that relatively non-invasive technology whose primary purpose is to diagnosis treatable disorders and cure them before or after birth would be warmly welcomed by parents and ethicist alike. However, the present reality is that antenatal diagnosis rarely leads to fetal therapy. In fact, in many cases normal fetuses are negatively effected from the CVS procedure [31]. There is also evidence that the availability of AND may be leading scientists to leave research on cures of genetic disorders in favour of selective abortion. During the 1960 s there were two to three times as many people working on a cure for Tay-Sachs disease than at present. The emphasis now is put on an antenatal diagnosis for Tay-Sachs disease, followed by abortion in the case of a test positive. Similarly, as soon as an antenatal diagnostic test for Huntington disease became available in the early 1980s, 'funds began to disappear for research to find a cure' [31]. Beside these trends, the greater social acceptability of abortion, and increased pressure on women to undergo AND from health insurance companies medical professionals and government agencies, are all possible negative consequences of AND. Alongside the benefits of diagnosing abnormalities in early stages 
of pregnancy, there are some potential psychological costs. These include anxiety, loss of confidence about the pregnancy and negative attitudes towards the baby. A major worry is, or ought to be, that the availability of AND may make people increasingly intolerant of the disabled and hostile towards parents who choose not to abort affected fetuses [5].

The use of AND for sex selection and termination of pregnancy if the fetus is of the undesired sex is, rightly, described as an atrociously unethical practice [32]. However, it is also easy enough to see the wish to have a boy or a girl as simply satisfying the desires or needs of the future parent(s) or other relatives. Strictly argued, sex preference could be regarded in the same way as exercising a preference for a normal, healthy child, rather than an unhealthy one. If someone has the right to do something to have (or not to have) a disabled child, he or she could argue the same right to have (or not to have) a child of particular sex. Strictly speaking, both properties, being healthy/disabled or male/female are morally, neutral. The reasoning follows: if it is right to terminate the pregnancy in case of disability, is it not equally right to terminate it in case of undesired sex, or vice versa. Mahoney observed that parents are necessarily determining a child's genetic constitution, its environment, its character and its entire future by the unavoidable choices they make, whether consciously or not: the choice to have a child, the choice to do so in a particular country or town or climate, the choice to send it to a particular school, the choice to encourage it or discourage it in certain forms of behaviour, and so on. He went on to conclude: "I do not see why, within such a chain of choices, the choice of sex should be singled out for particular moral disapproval" [33]. It is wrong, it could be argued, to differentiate undergoing an AND with the intention of finding out the health condition of the fetus with termination as a possibility, from undergoing an AND to check the sex of the fetus with, again, termination as a possibility. In principle, both can be seen as equally morally acceptable or unacceptable.

In 1883 Francis Galton started using the word 'eugenics' defining as the science of improving stock -not only by judicious mating, but whatever tends to give the more suitable races or strains of blood a better chance of prevailing over the less suitable than they otherwise would have had [34]. However, later the social policy intervention, along with genetics measures exists in many countries [34]. These policies do not aim to coerce or mandatory who will be conceived and born, they emphasise the elimination of hereditary disease and handicaps through antenatal testing. This eugenics thinking is justified by some, since it is not a science based on Nazism, racism, discrimination to minorities and genetic deter- minism. It is a science which inherent in the core eugenic doctrine of improving the stock of humankind by application of the science of human heredity. This science can be called 'negative eugenics'.

Despite all improvements, still ANT is not 100 per cent accurate. It is reported that: "Routine screening tests do not detect all cases. MS-AFP detects about 80 percent of cases of spina bifida. Although smaller, there is a false negative rate from both CVS and amniocentesis. Inherent in all screening tests is the possibility of a false positive result" [26]. The routine use of ultrasound may result in the detection of symptomless minor anomalies, the incidence and natural history of which are unknown. Although these are not indications for a termination, their detection means that women face the rest of their pregnancies with the knowledge that their child has an abnormality where implications are unknown. This may have two different consequences: the diagnosis of a possible abnormality may affect the acceptance of the baby by the parents and create negative attitudes in them towards it; or it may alert parents to prepare emotionally and psychologically for their (possibly) handicapped baby. In either case parents have 5-6 months to make up their minds-which is better than being surprised in the labour room.

For all couples with an abnormal result, there may be moral or religious objections or social pressures about termination, there may be disagreements between the couple as to the correct course of action and it is not always possible to give the couple a clear idea of the particular disability of that particular fetus. There is also the extremely important emotional consequence of the decision-the feeling of responsibility for the loss of a wanted child, which many couples describe as guilt. Clearly, in these situations, the decision making is more difficult, and for those couples who choose to terminate a pregnancy at less than 100 per cent risk of the fetus being affected, there will be lingering doubts about whether the baby might, after all, have been normal. A study has shown that in 38 per cent of the cases there are differences between the attitudes of parents towards AND [22]. While discussing the harms and the benefits of the antenatal screening programmes Atkins and Hey suggested that: "It is possible that some screening programmes currently do more harm than good. Antenatal diagnosis does not always increase a child's chance of survival. Liveborn children with an uncomplicated abdominal wall defect, for example, have an excellent chance of survival and a negligible risk of long-term disability, but antenatal diagnosis can bring with it ill-justified pressure for the pregnancy to be terminated" [1]. 


\section{In Whose Interest?}

There can be no objection if the aim of ANT procedure is to diagnose abnormality and cure it, if that is possible. However, many people are uneasy about terminating the life of the fetus. At this stage the question arises: "Whose interest does ANT serve-the interest of the child-to-be, or of the parents, or of the siblings' and/or of the society as a whole?" In the event of an abnormality being diagnosed, treatment before birth, or birth in a centre where the necessary interventions are possible, the child-to-be would definitely benefit from ANT. In this case everyone will have tried their best to give the unborn a (better) life. There is a question whether having a child with an abnormality is good for parents, siblings, or the society. In fact the interest of the child/person vis-à-vis having a life at all, overweighs others' comparatively trivial interests, for almost any interest is trivial compared to life. Of course, it is not convenient to have a disabled child/sibling/citizen; of course, everyone would prefer to have a healthy one. However, in AND and subsequent termination, the choice is not between being born with health or being born without it; rather, the choice is between a worldly existence or none at all. And the difference between existence and non-existence is beyond comparison [35].

Should we then admit that, except where pre- or post-natal treatment is the aim, AND has nothing to do with the prenate's interest, but with parents', siblings' and/or society interest? Several authors have said that much antenatal diagnosis is for the benefit of the parents rather than the fetus [36]. But is it that straightforward?

Does the birth of a disabled child not add to the suffering in the world? Harris has argued on one occasion that: "We have an obligation to prevent suffering and disability, or, more abstractly that we should try to produce a world with less rather than more suffering in it, that we should try to produce a happier world. So indeed there is clearly a moral obligation to provide such screening where possible so that parents can have the opportunity to choose not to bring suffering or disability into the world" [37]. A counterargument was put by Galjaard, a professor of cell biology: "Parents who have integrated their suffering, having had one or more handicapped children now stand up and defend the birth and the experience of these handicapped children as having made them happier, their marriage better, and so on" [37]. To this Harris replied with an analogy: "Imagine a pregnant woman has a condition. The fetus is damaged, but there is a simple risk-free procedure which will remove the damage. She just has to imbibe orange juice and the handicap will be removed. But she says no, she does not want to do it, she does not want this therapy because the last handicapped child she had made her so happy she intends to have another. What one would feel about such a decision gives the key to the respectability of the happiness argument from other people's misery" [37]. As I have argued elsewhere in discussing this analogy, if all that is needed is 'to imbibe orange juice and remove the handicap', then drinking orange juice is the only course of action that any sensible person would take [38]. But in reality there is rather more involved, and rather more at stake, than a simple drink of orange. The ANT procedure is not risk free (as we saw, above). Thereafter, the choice is not 'drink orange juice and have a healthy baby', which the mother perversely refuses because she 'prefers' to have a disabled child. Rather, the choice is (after the risk of ANT): have a child who may have disability or not have the child, i.e. terminate your pregnancy.

Furthermore, some genetic disorders are diagnosed antenatally which may not surface for many years after birth, and possibly only after the parents themselves are deceased. Huntington's chorea would be a case in point. In this circumstance, should termination follow ANT, although there is 20 or 30 years of happy, normal life expectancy? Harris answered the question in this way: "I think it would be better not to bring that degree of suffering, albeit postponed, into the world. Taking a decision when no person is in being is quite different from saying to a 20 year-old who has Huntingdon's and who will die from it that their life has not been worth having. When it is an embryo or a fetus, before it has a conscious life, the calculation to be made is which action causes the least suffering, and I think termination is the answer to that question" [37]. First of all we must admit that the comparison to be made is not that between nonexistence and a deprived life but that between a defective life and the life of a normal child. Of course it would be better not to bring that degree of suffering into the world. And, it is absolutely preferable to take a decision when there is as yet, 'no person in being'. However as soon as an individual life is being, there is no point in comparing that life, however deprived it may be, with non-existence. This does not mean rejecting outright the possibility that there are some situations in which it is better to be dead. But that is a decision for the individual concerned, not a decision for others to take, whoever they are.

In sum, there are two questions before us: 1) determine the 'morally safe' period to manipulate the prenate, and 2) to improve AND techniques to in order to detect abnormalities within the 'safe' period. As was argued elsewhere, the 'morally safe' period could be up to the eighth week after conception [39], unless the zygote's normal development has been prevented by some measure such as freezing. During this period it is morally less problematic to check the prenate's state of health because, should we decide not to carry on the prenate's life, we would not 
be intervening in and terminating an individual human life, a distinct person. Now the only AND technique currently available to enable us to test the prenate's state of health during the 'safe' period is preimplantation diagnosis (PID). It is carried out in the first week of gestation and before implantation; it does not pose any medical or moral problem. PID therefore the most reliable and morally acceptable of the current ANT techniques [12].

\section{Conclusion}

In conclusion we can say that, although there are different views in the wide bioethics community, antenatal screening and antenatal diagnosis are new technologies developed to contribute to our happiness and welfare, but like many other new technologies, they are accompanied by new moral controversies. It is not proper to conclude that "ANT is good", or "ANT is evil"; deciding this issue is firmly attached to a number of ethical dilemmas at the heart of which is the 'moral status of the prenate'. So, deciding the issue is dependent upon the views of the person, and a case-by-case approach can be suggested. If any embryological stage is defined as the beginning of a human individual, only testing but not termination may be allowed. We have stressed the vital importance of providing the parents with good counselling before and after ANTs. The aim of good counselling is to inform and enable parental understanding and choices with respect to their unborn child; health care professionals should not impose their own beliefs upon the parents [40]. What they can and must do is to debate the issues among themselves, to review their criteria for advising ANT procedures, and for the choices that may follow, so that they are providing the best possible service to their patients who are, of course, 'persons', a category which the prenates may also belong, at least in the minds and hearts of their parents.

\section{Competing interests}

None declared

\section{References}

I. Atkins AFC, Hey EN: The Northern Regional Fetal Abnormality Survey. In Antenatal Diagnosis of Fetal Abnormalities (Editted by JO Drife, D Donnai), Springer-Verlag Ltd., London, 199| I3-34

2. Whittle MJ: Routine Fetal Anomaly Screening. In Antenatal Diagnosis of Fetal Abnormalities (Editted by JO Drife, D Donnai), Springer-Verlag Ltd., London, 199135-43

3. : The Hereditary Diseases Program, WHO, Geneva, 198510

4. Hoedemaekers R, Have H, Chadwick R: Genetic Screening: A Comparative Analysis of Three Recent Reports. Journal of Medical Ethics 1991, 23:135-41

5. Sutton A: Prenatal Diagnosis: Confronting the Ethical Issues. The Linacre Centre, London, I99020-I

6. Gert B, et al: Morality and the New Genetics. Jones and Bartlett Publishers, Sudbury (Massachusetts), 1996202

7. Edward RG, Purdy J: Human Conception in Vitro. Academic Press, London, 1981373

8. Aksoy S: Moral Controversies on Preimplantation Genetic Testing. in Bioethics in Asia (Edited by N Fujiki, DRJ Macer). Eubios Ethics Institute Publications, Christchurch, NZ, 1998249-52
9. Meith D: In Vitro Fertilisation: From Medical Reproduction to Genetic Diagnosis. Biomedical Ethics 1996, I (1):6-8

10. Farrant W: Who's for Amniocentesis?: The Politics of Prenatal Screening. in The Sexual Politics of Reproduction (Edited by $\mathrm{H}$ Homans). Gower Publishing Comp. Ltd., Hants, 198596-122

II. : Reducing the Risk: Safer Pregnancy and Childbirth. HMSO, London, 197748

12. Aksoy S: Ethical Issues Surrounding Prenatal Testing. T. Klin. Journal of Medical Ethics 1998, 6(2):69-72

13. Aksoy S: Saglik Kaynaklarinin Dagitiminda ve Tedavi Kararinin Verilmesinde Kullanilan Kriterlerin Etik Tartismasi. (Ethical Discussion of Criteria Used in Distribution of Health Care Resources). 3rd Turkish Medical Ethics Symposium Proceedings Ankara, 199723-25

14. : Report by the Working Group on Screening for Neural Tube Defects, DHSS, London, 197928

15. Danish Council of Ethics Annual Report. Bulletin of Medical Ethics 1999, | 5 |:3-5

16. : Prenatal Diagnosis and Genetic Screening: Community and Service Implications, London, 1989

17. Aksoy S: Abortion: Destruction of Life. Eubios J of Asian and International Bioethics 1997, 7(2):52-4

18. Marteau TM: Psychological Implications of Prenatal Diagnosis. In Antenatal Diagnosis of Fetal Abnormalities (Editted by JO Drife, $D$ Donnai), Springer-Verlag Ltd., London, 1991243-54

19. Rothman B: The Tentative Pregnancy: Prenatal Diagnosis and the Future of Motherhood, Viking Penguin, New York, 1986230

20. Demirhan-Erdemir A: Genetic Diseases in Need of Genetic Counselling and Their Importance in Medical Ethics. T. Klin. Journal of Medical Ethics 1998, 6(2):73-82

21. Abramsky L: Counselling Prior to Prenatal Testing. In: Prenatal Diagnosis: The Human Side (Edited by L Abramsky, J Chapple).Chapman \& Hall, London, 199470-85

22. Sjogren B, Uddenberg N: Decision Making During the Prenatal Diagnostic Procedure. A Questionnaire and Interview Study of 2 I I Women Participating in Prenatal Diagnosis. Prenatal Diagnosis 1988, 8:263-73

23. Chadwick RF: What Counts as Success in Genetic Counselling? Journal of Medical Ethics 1993, 19:43-6

24. Gillon R: Genetic Counselling, Confidentiality and the Medical Interests of Relatives. Journal of Medical Ethics 1988, 14:171-2

25. Tükun A, Bökesoy I: Ethical Aspects in Genetic Research. Eubios J. of Asian and International Bioethics 1998, 8(6): 178-9

26. Marteau TM, et al: 'Development of A Self-administered Questionnaire To Measure Women's Knowledge of Prenatal Screening and Diagnostic Tests. Journal of Psychosomatic Research 1988, 32:403-8

27. Carmenisch P: Abortion: For the Fetus's Own Sake. Hastings Centre Report 1976, 6:38

28. Whelton JM: Sharing the Dilemmas: Midwives' Role in Prenatal Diagnosis and Fetal Medicine. Profess Nurse 19905 I4-8

29. Clarke A: Genetics, Ethics, and Audit. The Lancet 1990, 335: I I45-

30. Clarke A: Is Non-directive Genetic Counselling Possible? The Lancet |99|, 338:998-100|

31. Boss JA: First Trimester Prenatal Diagnosis: Earlier is not Necessarily Better. Journal of Medical Ethics 1994, 20:146-5 I

32. Kusum : The Use of Pre-natal Diagnostic Techniques for Sex Selection: The Indian Scene. Bioethics 1932, 7(2/3): 1 49-65

33. Mahoney J: The Ethics of Sex Selection. In:Medicine, Medical Ethics and the Value of Life. (Editwed by P Byrne) John Wiley \& Sons, Chichester, 1990141-57

34. Wang Y: A Call for A New Definition of Eugenics. Eubios J. of Asian and International Bioethics 1999, 9(3):73-4

35. Aksoy S: To Value Life and Existence. Eubios Journal of Asian and International Bioethics 1997, 7(4): 102-4

36. Henderson JB: Economic Aspects of Prenatal Diagnosis. In. Antenatal Diagnosis of Fetal Abnormalities (Editted by JO Drife, D Donnai), Springer-Verlag Ltd., London, $1991269-78$

37. Harris J: Ethical Aspects of Prenatal Diagnosis. In. Antenatal Diagnosis of Fetal Abnormalities (Editted by JO Drife, D Donnai), Springer-Verlag Ltd., London, 1991279-96

38. Aksoy S: Prenatal Testing: An Ethical Perspective. The New J. of Medicine 1996, I3(2): 12-4

39. Aksoy S: Personhood: A Matter of Moral Decisions, Eubios J. of Asian and International Bioethics 1997, 7(1):3-4 
40. Aydin E: Informed Consent and prenatal diagnosis. Sendrom 1999, II(10):126-9

\section{Pre-publication history}

The pre-publication history for this paper can be accessed here:

http://www.biomedcentral.com/content/backmatter/ 1472-6939-2-3-b1.pdf

Publish with BioMedcentral and every scientist can read your work free of charge

"BioMedcentral will be the most significant development for disseminating the results of biomedical research in our lifetime."

Paul Nurse, Director-General, Imperial Cancer Research Fund

Publish with BMc and your research papers will be:

- available free of charge to the entire biomedical community

- peer reviewed and published immediately upon acceptance

- cited in PubMed and archived on PubMed Central

- yours - you keep the copyright

Submit your manuscript here:

http://www.biomedcentral.com/manuscript/
BioMedcentral com

editorial@biomedcentral.com 